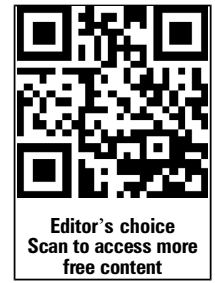

${ }^{1}$ Department of Respiratory and Sleep Medicine, Women's and Children's Hospital, Adelaide, South Australia, Australia

${ }^{2}$ Murdoch Children's Research Institute, Melbourne, Victoria, Australia

${ }^{3}$ Royal Children's Hospital Melbourne, Melbourne, Victoria, Australia

${ }^{4}$ Department of Allergy, Immunology and Respiratory Medicine, The Alfred Hospital, Prahran, Victoria, Australia ${ }^{5}$ Respiratory Medicine, Royal Children's Hospital Melbourne, Parkville, Victoria, Australia

\section{Correspondence to} Dr Andrew Tai,

Dept of Respiratory and Sleep Medicine, Women's and Children's Hospital, 72 King William Road, North Adelaide, Adelaide, South Australia 5006, Australia;

andrew.tai@health.sa.gov.au

Received 14 November 2013 Revised 5 January 2014 Accepted 15 February 2014 Published Online First 19 March 2014

\title{
The association between childhood asthma and adult chronic obstructive pulmonary disease
}

\author{
Andrew Tai, ${ }^{1}$ Haily Tran, $^{2}$ Mary Roberts, ${ }^{3}$ Nadeene Clarke, ${ }^{2}$ John Wilson, ${ }^{4}$ \\ Colin F Robertson ${ }^{2,5}$
}

\section{ABSTRACT}

Introduction There is epidemiological evidence to suggest that events in childhood influence lung growth and constitute a significant risk for adult COPD. The aim of the study is to evaluate for an association between childhood asthma and adult COPD.

Methods This longitudinal, prospective study of 6-7year-old children with asthma has been regularly reviewed every 7 years to the current analysis at 50 years of age. Participants completed respiratory questionnaires and lung function spirometry with postbronchodilator response. At the age of 50, subjects were classified to the following subgroups: non-asthmatics, asthma remission, current asthma and COPD which was defined by $\mathrm{FEV}_{1}$ to FVC ratio postbronchodilator of less than 0.7 . Results Of the remaining survivors, 346 participated in the current study (participation rate of $76 \%$ ) of whom 197 completed both questionnaire and lung function testing. As compared with children without symptoms of wheeze to the age of 7 , (non-asthmatics) children with severe asthma had an adjusted 32 times higher risk for developing COPD (95\% Cl 3.4 to 269). In this cohort, $43 \%$ of the COPD group had never smoked. There was no evidence of a difference in the rate of decline in $\mathrm{FEV}_{1}$ (mL/year, 95th $\mathrm{Cl}$ ) between the COPD group $(17,10$ to 23) and the other groups: non-asthmatics $(16,12$ to 21), asthma remission (20, 16 to 24) and current asthma (19, 13 to 25).

Conclusions Children with severe asthma are at increased risk of developing COPD.

\section{INTRODUCTION}

COPD is an umbrella term for a spectrum of diseases characterised by airflow obstruction that is not fully reversible, resulting from a combination of small airway disease and parenchymal destruction. While the main risk factors for the development of COPD are genetic and inhalational exposures such as tobacco smoke, failure to attain maximal lung growth during childhood constitutes a significant risk. In the 1970s, Burrows et al reported that adults with COPD were more likely to recall respiratory troubles during childhood than those without COPD, suggesting the possible progression of childhood asthma into adult COPD. In the early 1960s, Orie and colleagues proposed that 'asthma, chronic bronchitis and emphysema should be considered different expressions of one disease entity in which both host factors (such as genetic predisposition to atopy and bronchial hyperresponsiveness) and environmental factors (such as smoking) play major roles'. ${ }^{2}$

\section{Key messages}

What is the key question?

- Do children with asthma develop COPD in adult life?

\section{What is the bottom line?}

- Children with severe asthma are at increased risk of developing adult COPD whereas children with intermittent asthma are not at increased risk of developing adult COPD.

\section{Why read on?}

- This study is the longest and most comprehensive study of childhood asthma followed to the age of 50 and highlights that suboptimal lung growth in childhood is a precursor to adult COPD.

In the Tuscon Epidemiological Study of Airways Obstructive Disease (TESAOD), 3099 adult subjects over 20 years of age were randomly selected and subsequently followed up over 20 years. ${ }^{3}$ The results of the study indicated that adult subjects with active asthma had a 10 times higher risk of acquiring symptoms of chronic bronchitis, 17 times higher risk of receiving a diagnosis of emphysema and 12.5 times higher risk of fulfilling COPD criteria, even after adjusting for smoking history and potential confounders. In the large follow-up of the European Community Respiratory Health Survey, subjects with a history of childhood asthma had a 10 -fold increased risk of developing COPD. ${ }^{4}$ In the most recent follow-up of the Tuscon birth cohort to the age of 22, poor airway function shortly after birth was recognised as a risk factor for airflow obstruction in young adults and these subjects would reach the threshold of $\mathrm{FEV}_{1}$ and $\mathrm{FEV}_{1}$ to $\mathrm{FVC}$ ratio that define COPD at an earlier age. ${ }^{5}$

The synergistic impact of smoking and asthma on lung function decline has been demonstrated in adult studies. ${ }^{6}$ with the Dunedin cohort reporting follow-up from childhood years and demonstrating that smoking was a risk factor for persistent wheezing and subsequent reduced lung function at the age of $26^{8}$

It is increasingly apparent that COPD often has its roots decades before the onset of symptoms. Impaired growth of lung function during childhood and adolescence, caused by premature gestation, asthma, recurrent infections or tobacco smoking, 
may lead to lower maximally attained lung function in early adulthood and also predispose to development of COPD. ${ }^{9}$ Therefore, the aim of this study was to explore the association between childhood asthma into adult COPD. Some of the results of this study have been previously reported in the form of an abstract. ${ }^{10}$

\section{METHODOLOGY}

This study was approved by the Human Research Ethics Committee of the Royal Children's Hospital Melbourne. All subjects provided consent prior to participation.

\section{Study design and cohort}

The Melbourne Asthma Cohort was recruited from a 1957 birth cohort at the age of 7 which has been previously described $^{11}$ and comprehensively reviewed from the age of 7 to the current study at the age of $50 .{ }^{12-16}$ In brief, a modified random sampling strategy was used to select 401 subjects, following a survey of 30000 Grade 2 Melbourne primary school children in 1963-1964. The survey included a parent completed questionnaire which was followed by a parent interview and physical examination of the child by members of the research team. All those children with a history of asthma or wheezy bronchitis (WB) were included in the study and one in two with mild wheezy bronchitis (MWB) and one in 20 controls were included. When the children were reviewed at the age of 10 , it was realised that there were very few with severe asthma (SA), and a further sampling of 21000 children was performed from the same birth cohort to establish an SA group which included 83 children.

The original groups were classified as follows: control or nonasthmatics-105 children who had never wheezed; MWB-74 children with fewer than five episodes of wheezing associated with bronchitis; WB-104 children with five or more episodes of wheezing associated with bronchitis; asthma-113 children with wheezing not associated with respiratory tract infection; and SA -83 children with onset of symptoms before 3 years of age, persistent symptoms at 10 years of age, barrel-chest deformity and or $\mathrm{FEV}_{1}$ to $\mathrm{FVC}$ ratio to $50 \%$ or less (of which only three had a $\mathrm{FEV}_{1}$ to FVC ratio under $50 \%$ ). The group of children with MWB and WB would now be regarded as children with intermittent asthma.

\section{Interviewer-administered questionnaire}

At the current study, an interviewer-administered questionnaire was performed to collect details on the frequency of wheeze, symptoms of chronic bronchitis (defined as daily moist productive cough for at least 3 months over two successive years), frequency of hay fever and eczema symptoms and smoking behaviour. Childhood hay fever (data collected at the age of 7) was defined as children who had symptoms of sneezing, nasal itching, runny or blocked nose in the absence of a cold or flu at recruitment. Childhood eczema (data collected at the age of 7) was defined as children who had symptoms of dry, itchy rash localised to flexural regions, facial or generalised to the body at recruitment. Current smoker was defined as subjects who smoked regularly within the last 12 months. Ever smoker was defined as subjects who have had a smoking history of at least 1 pack year or more. The St George's Respiratory Questionnaire was used as a valid measure of activity limitation with a low score indicating a better health related quality of life. The threshold for a clinically significant difference between and within groups of patients is four units. ${ }^{17}$ Subjects who were not able to present to the hospital had the questionnaire administered by telephone.

\section{Lung function testing}

Lung function testing was performed on all subjects who presented to the hospital for assessment. The test was carried out by a trained respiratory scientist using the Masterscreen body plethysmograph (Jaegar, Germany). Forced expiratory manoeuvres were performed according to American Thoracic Society/European Respiratory Society standards. ${ }^{18} \mathrm{FEV}_{1}, \mathrm{FVC}$ and $\mathrm{FEV}_{1}$ to $\mathrm{FVC}$ ratio were the variables used for analysis. Spirometry was repeated following administration of $600 \mu \mathrm{g}$ dose of salbutamol. A postbronchodilator increase in $\mathrm{FEV}_{1}$ of $200 \mathrm{~mL}$ or $12 \%$ defined reversibility. ${ }^{18}$ COPD was defined according to the GOLD criteria: $\mathrm{FEV}_{1}$ to $\mathrm{FVC}$ ratio postbronchodilator of less than $0.7 .^{19}$

\section{Statistical analysis}

For the follow-up at 50 years, the cohort was classified as follows.

Non-asthmatics: Those who were originally in the nonasthmatic childhood group and remained wheeze-free throughout the study period.

Asthma remission: Those who were originally in one of the four symptomatic groups at recruitment who had been wheezefree and not taken asthma medication in the preceding 3 years.

Current asthma: Those who were originally in one of the four symptomatic groups or non-asthmatic group at recruitment and who had asthma symptoms or had taken asthma medication for the preceding 3 years.

COPD: Postbronchodilator $\mathrm{FEV}_{1}$ to $\mathrm{FVC}$ ratio $<0.7$ group who were defined at the age of 50 .

The statistical software Stata V.10.0 for Windows (Stata Corporation, Texas, USA) was used for data analysis. Symptom outcomes of the age 50 groups were determined with $\chi^{2}$ testing compared with the non-asthmatic group. Univariate and multivariate logistic regression was used to determine the clinical predictors of childhood factors into adult COPD. The childhood non-asthmatic group was used as the reference comparison group. The following variables were tested on multivariate analysis: childhood SA, asthma, WB groups, male sex, ever smoker, current smoker at the age of 50 , childhood hay fever and childhood eczema. Two-sided Student $t$ tests were used to compare prebronchodilator and postbronchodilator lung function measures at the age of 50 between the age 50 groups and the nonasthmatic group. The rate of decline in $\mathrm{FEV}_{1}$ was calculated separately for each subject with at least two time point measurements between the ages of 21 and 50 via a linear regression. The age of 21 was taken as the time when maximal lung function would have been attained. The effects of smoking at the age of 21 (binary outcome), smoking at the age of 50 (binary outcome), and sex on the rate of decline in $\mathrm{FEV}_{1}$ were examined using multivariate linear regression. The rate of decline in $\mathrm{FEV}_{1}$ to FVC ratio was calculated separately for each subject with at least two time point measurements between the ages of 10 and 50 via a linear regression. The overall difference in the rate of decline in $\mathrm{FEV}_{1}$ and $\mathrm{FEV}_{1}$ to $\mathrm{FVC}$ ratio across the age 50 groups was examined using an analysis of variance.

\section{RESULTS}

\section{Subject recruitment}

Of the original 484 participants, 21 had died ( 2 due to asthma) and five original records were lost. Of the available 458 participants, 34 refused contact and 78 were lost to follow-up. In all, 
Table 1 Distribution of subjects at recruitment and the age of 50

\begin{tabular}{|c|c|c|c|c|}
\hline & \multirow[b]{2}{*}{$\begin{array}{l}\text { Recruitment } \\
n=479\end{array}$} & \multicolumn{3}{|l|}{ Age 50} \\
\hline & & $\begin{array}{l}\text { Deceased } \\
n=21\end{array}$ & $\begin{array}{l}\text { Followed up } \\
n=346(76 \%)\end{array}$ & $\begin{array}{l}\text { Lung function } \\
\text { test performed } \\
n=197(43 \%)\end{array}$ \\
\hline $\begin{array}{l}\text { Control } \\
\text { (non-asthmatics) }\end{array}$ & $105(22 \%)$ & 5 & 77 (22\%) & $48(24 \%)$ \\
\hline $\begin{array}{l}\text { Mild wheezy } \\
\text { bronchitis }\end{array}$ & $74(15 \%)$ & 3 & $50(14 \%)$ & $23(12 \%)$ \\
\hline Wheezy bronchitis & $104(22 \%)$ & 6 & $78(23 \%)$ & $43(22 \%)$ \\
\hline Asthma & 113 (24\%) & 2 & 81 (24\%) & $49(25 \%)$ \\
\hline Severe asthma & $83(17 \%)$ & 5 & 60 (17\%) & $34(17 \%)$ \\
\hline Male (\%) & $61 \%$ & $81 \%$ & $60 \%$ & $63 \%$ \\
\hline
\end{tabular}

346 subjects were recruited representing a participation rate of $76 \%$ of which all subjects had completed the questionnaires and 197 (43\%) subjects had also completed lung function testing as well. The mean age of participants was $51.4( \pm 0.9)$ years. The participation rate did not differ markedly between recruitment groups (table 1) and the proportion of the subjects who performed lung function testing was representative of the original recruitment group.

\section{COPD demographics}

In this cohort, 28/197 (14\%) subjects had COPD. Of the 28 subjects, $22(79 \%)$ were men and $6(21 \%)$ were women. In the COPD group, 16/28 (57\%) had a history of smoking and 12/28 $(43 \%)$ had never smoked. The prevalence rates of both current smokers and ever smokers were proportional in all groups at 50 years of age.

\section{Outcomes at the age of $\mathbf{5 0}$}

Children in the MWB and WB groups had the highest prevalence of asthma remission at the age of $50(48 \%$ and $56 \%$, respectively) compared with the SA group (15\%). Overall, 44\% of children with SA fulfilled the diagnosis of COPD at the age of 50 (table 2). In this study, $7 / 28(25 \%, \mathrm{p}=0.01)$ of the subjects with COPD at the age of 50 had symptoms of chronic bronchitis compared with $1 / 41(2 \%)$ of the non-asthmatic, $2 / 58$ $(3 \%, \mathrm{p}=0.8)$ of asthma remission and $11 / 70(16 \%, \mathrm{p}=0.03)$ of current asthma groups. When compared with non-asthmatics (mean activity limitations score \pm 95 th CI 6.9 ; 3.7 to 10.1 ), adults with current asthma $(22.4 ; 17.1$ to $27.6, \mathrm{p}<0.001)$ and COPD $(12.9 ; 8.2$ to $17.6, \mathrm{p}=0.03)$ had both statistically and clinically significant deficits in activity limitation scores. In the subjects with COPD and chronic bronchitis at the age of 50 $(n=7)$, six had a smoking history and had smoked in the last

Table 2 Outcome at the age of 50 by recruitment groups

\begin{tabular}{lllc}
\hline & Asthma remission $(\mathbf{n}=57)$ & Current asthma $(\mathbf{n}=65)$ & COPD $(\mathbf{n}=\mathbf{2 7})$ \\
\hline MWB & $11 / 23(48 \%)$ & $11 / 23(48 \%)$ & $1 / 23(4 \%)$ \\
WB & $24 / 43(56 \%)$ & $16 / 43(37 \%)$ & $3 / 43(7 \%)$ \\
A & $17 / 49(35 \%)$ & $24 / 49(49 \%)$ & $8 / 49(16 \%)$ \\
SA & $5 / 34(15 \%)$ & $14 / 34(41 \%)$ & $15 / 34(44 \%)$ \\
\hline \multicolumn{2}{c}{ A, asthma; MWB, mild wheezy bronchitis; SA, severe asthma; WB, wheezy bronchitis. }
\end{tabular}

12 months. In the subjects with COPD and no history of chronic bronchitis $(\mathrm{n}=21), 10$ had a smoking history and had smoked in the last 12 months.

\section{Childhood predictors of adult COPD}

On univariate analysis, a significantly increased OR (OR, 95th CI) was found for the childhood asthma and SA (37.1, 4.6 to 301) groups and the diagnosis of COPD at the age of 50. Following multivariate analysis, the increased OR was strengthened for the childhood SA group. There was no significantly increased OR for sex, childhood WB groups, childhood hay fever or eczema, current smoker or ever smoker categories with COPD at 50 years of age (table 3 ).

\section{Lung function at the age of 50 and trend from childhood years}

At the age of 50 , the mean $\mathrm{FEV}_{1} \%$ predicted (95th $\mathrm{CI}$ ) in those with current asthma $(92,88$ to $97 ; \mathrm{p}<0.005)$, asthma remission $(104,100$ to $108 ; \mathrm{p}<0.05)$ and COPD $(85,81$ to $90 ; \mathrm{p}<0.005)$ were reduced compared with those who were in the nonasthmatic group $(111,107$ to 115$)$. Mean $\mathrm{FEV}_{1}$ to FVC ratio (95th CI) in those with current asthma $(71,69$ to $73, \mathrm{p}<0.005)$ and $\operatorname{COPD}(63,61$ to $65 ; \mathrm{p}<0.005)$ were reduced compared with those who were in the non-asthmatic group (78, 76 to 80$)$.

Further analysis of the group with COPD demonstrated that the mean $\mathrm{FEV}_{1} \%$ predicted (95th CI) in those who were smokers $(86,78$ to $94 ; \mathrm{p}=0.7)$ were similar to those who were non-smokers $(85,79$ to 90$)$. The mean $\mathrm{FEV}_{1}$ to $\mathrm{FVC}$ ratio (95th CI) in those who were smokers $(63,60$ to $66 ; \mathrm{p}=0.8)$ were similar to those who were non-smokers $(63,60$ to 65$)$.

The reduced lung function seen in those with COPD and current asthma at 50 years was clearly established in the childhood years (figure 1). In the COPD group, there is a lack of increase in \%predicted $\mathrm{FEV}_{1}$ when compared with the nonasthmatic, asthma remission and current asthma groups during the age of $14-21$.

\section{The rate of decline in lung function across recruitment of age $\mathbf{5 0}$ groups}

For each group at age 50, the rate of decline and 95\% CI in $\mathrm{FEV}_{1}$ (mL/year) from age 21 to 50 and $\mathrm{FEV}_{1}$ to $\mathrm{FVC}$ ratio (percentage points/year) from age 10 to 50 is shown in figure 2 . The rate of decline in $\mathrm{FEV}_{1}$ (mL/year, 95th CI) is similar across all groups: non-asthmatic 16 (95th CI 12 to 21), asthma remission 20 (95th CI 6 to 24), current asthma 19 (95 th CI 13 to 25) and COPD 17 (95th CI 10 to 23) There was no evidence of an association among the rate of decline in $\mathrm{FEV}_{1}$ and sex, smoking at the age of 21 and smoking at the age of 50 .

Table 3 The childhood predictors of adult COPD

\begin{tabular}{lcc}
\hline & $\begin{array}{l}\text { OR }(95 \% \mathrm{CI}) \\
\text { (univariate) }\end{array}$ & $\begin{array}{l}\text { OR (95\% CI) } \\
\text { (multivariate) }\end{array}$ \\
\hline Severe asthma & $37.1(4.6$ to 301$)$ & $31.9(3.4$ to 269$)$ \\
Asthma & $9.1(1.1$ to 76.4$)$ & $9.6(1.0$ to 77$)$ \\
Wheezy bronchitis & $3.5(0.4$ to 35.2$)$ & \\
Mild wheezy bronchitis & $2.1(0.1$ to 35.8$)$ & \\
Male sex & $2.4(0.9$ to 6.3$)$ & \\
Ever smoker & $1.0(0.5$ to 2.3$)$ & \\
Current smoker & $1.1(0.5$ to 2.4$)$ & \\
Childhood hay fever & $1.0(0.3$ to 3.8$)$ & \\
\hline
\end{tabular}



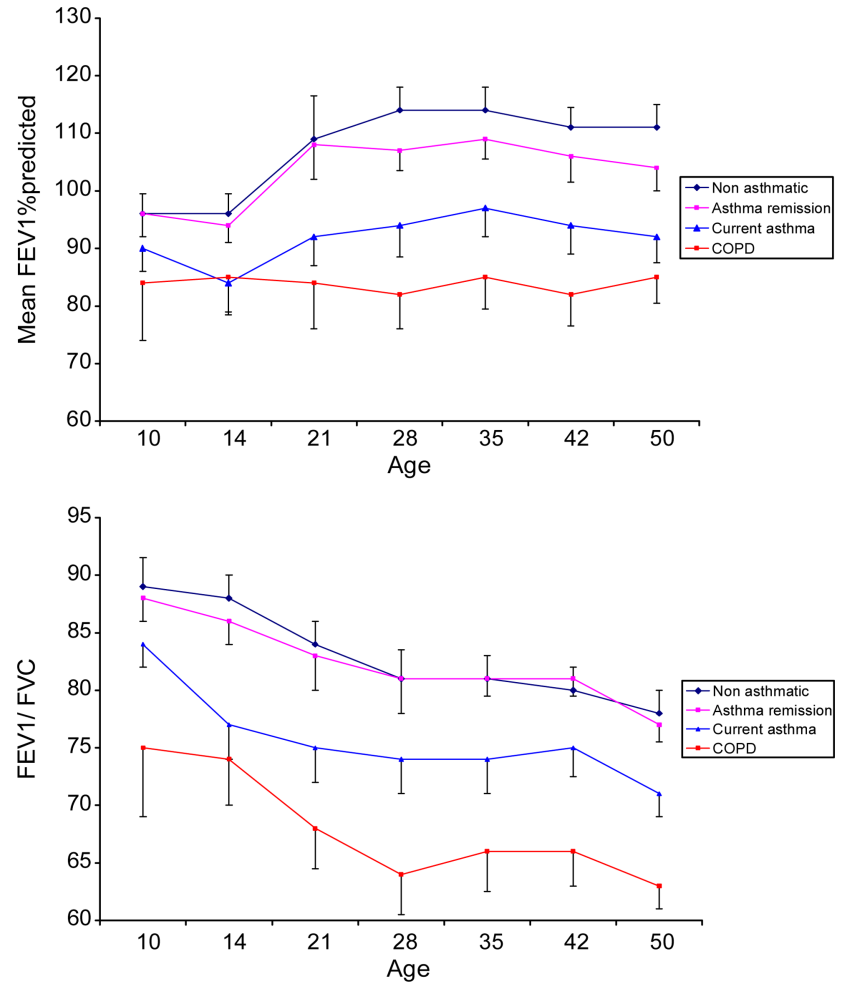

Figure 1 Trend in mean $\mathrm{FEV}_{1}$ per cent predicted and $\mathrm{FEV}_{1}$ to $\mathrm{FVC}$ ratio over time (95th $\mathrm{Cl})$.

There was no evidence of a difference in the rate of decline in $\mathrm{FEV}_{1}$ to $\mathrm{FVC}$ ratio (\% points/year, 95th $\mathrm{CI}$ ) across the age 50 groups: non-asthmatic 0.27 (95th CI 0.22 to 0.32 ); asthma remission 0.25 (95th CI 0.21 to 0.29 ); current asthma 0.27 (95th CI 0.21 to 0.32 ); and COPD groups 0.27 (95th CI 0.18 to 0.37$)$.

\section{CONCLUSIONS}

In this longitudinal follow-up study, it is clear that children with SA are at increased risk of developing adult COPD by 50 years of age. Children with intermittent asthma and persistent asthma are not at increased risk of developing COPD. When compared with the recent follow-up of the European Community Respiratory Health Survey, subjects who had reported a childhood history of asthma similarly reported a 10 -fold increased risk of developing COPD. ${ }^{4}$

Findings from cross-sectional studies of hospital-based samples of asthmatics suggest that asthma alone can cause persistent, non-reversible airflow obstruction and that the degree of obstruction is a function of the duration and severity of previous asthma. $^{2021}$ Reversibility of pulmonary obstruction in response to treatment, a hallmark of asthma, may decrease over time in some patients with moderate or SA, to the point of irreversible or only partially reversible airway obstruction. In the TESAOD study group, the investigators did not have information on response to bronchodilator, leaving unanswered the question of progression of asthma into COPD. ${ }^{3}$

The lung function outcome of the group with COPD adds to the work of Stern et $a l^{5}$ who followed the Tuscon birth cohort group indicating that infants with reduced lung function continue to track at lower levels to the age of 22 . The results of this study highlight the importance of suboptimal lung function growth in childhood as a predisposing factor towards adult
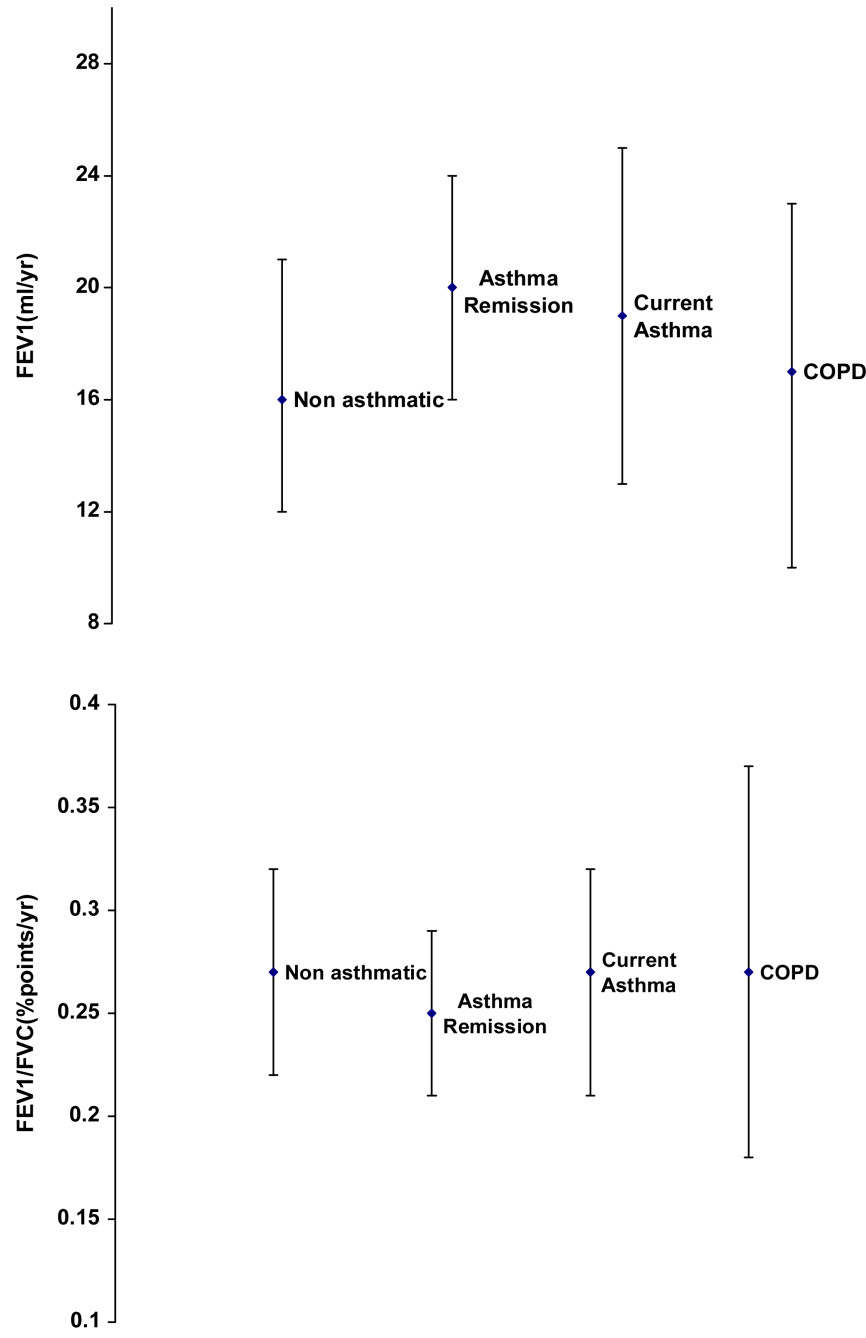

Figure 2 Rate of decline and $95 \% \mathrm{Cl}$ in lung function in $\mathrm{FEV}_{1}$ (from the age of 21 to 50 ) and $\mathrm{FEV}_{1}$ to FVC ratio (from the age of 10 to 50).

COPD. Recent reviews by Bush ${ }^{22}$ and Narang and Bush ${ }^{23}$ highlight the interaction between adverse maternal factors (such as smoking, atopy, infection) on the antenatal lung, childhood factors (such as candidate genes, asthma, infections, premature gestation) on lung growth and environmental risk factors (such as air pollution, smoking) as predisposing factors towards the development of COPD. During the period of adolescence, it was also noted that the adults who subsequently developed COPD did not have an increase in lung function growth as compared with the other groups which may suggest another mechanism contributing as a precursor to the development of COPD.

Tobacco smoke is by far the most important risk factor for COPD worldwide, but it is well recognised that only a fraction of smokers develop COPD and no less than a fourth of cases of COPD are unrelated to smoking. ${ }^{24}$ In the past decade, there have been emerging population-based studies reporting nonsmoking COPD as much higher than previously believed with prevalence reported between $15 \%$ and $50 \%$ worldwide. Other risk factors included air pollution, occupational exposures, lower respiratory childhood infections, chronic asthma, poor nutrition and environment interaction with candidate genes. ${ }^{25}$ As part of the Copenhagen City Heart Study, 9\% of subjects who were non-smokers developed COPD over a 25-year follow-up. ${ }^{26}$ In this cohort, a substantial subset of our COPD cohort have never smoked, confirming a phenotype of COPD 
which is potentially related to childhood asthma. In our cohort, $25 \%$ of the subjects with COPD had symptoms of chronic bronchitis, adding to the heterogenous nature and varying phenotype of COPD in adult life. Beasley and colleagues suggest that COPD should be considered as a syndrome of different disorders with distinct pathophysiological processes and treatment responses and, therefore, it would be important to define, identify and treat the different components of this complex disorder. $^{27}$ The synergistic impact of smoking and asthma on lung function has been demonstrated in the adult studies as well. ${ }^{67}$ This has not been well described in longitudinal childhood asthma studies. The combination of asthma and smoking $>15$ cigarettes per day had a synergistic effect on the decline in lung function, and resulted in a $17.8 \%$ decline in $\mathrm{FEV}_{1}$ over 10 years in the CARDIA study. ${ }^{7}$ In this study, we found no increase in the rate of decline in lung function of the current asthma and COPD groups when compared with the non-asthmatics when the smoking behaviour was taken into account. Due to the difficulty in extracting accurate smoking behaviour and varying subject attendance at different time points, we were not able to subdivide the impact of smoking behaviours (eg, continuous smokers, quitters) and total pack year smoking history on the decline in lung function. Therefore, the true impact of smoking has to be interpreted with caution as it is clearly underpowered to measure the effect on lung function decline.

Airway remodelling is characterised by functionally relevant changes of the cellular and molecular constituents of the airway wall that are linked to the surrounding inflammatory process. $^{28} 29$ Airway inflammation and remodelling have been documented in young children with asthma ${ }^{30-32}$ and is postulated to be linked among patients with asthma to the development of non-reversible airway obstruction and accelerated $\mathrm{FEV}_{1}$ decline. ${ }^{33-35}$ However, to date, this association is far from being fully elucidated. Indirect evidence is provided by Benayoun et $a l^{36}$ in which fibroblast accumulation and airway smooth muscle hypertrophy in proximal airways were found to characterise severe persistent asthma and to correlate negatively with both prebronchodilator and postbronchodilator $\mathrm{FEV}_{1}$ values among patients with asthma. An inclusion criterion for children recruited to the SA group was either $\mathrm{FEV}_{1}$ to $\mathrm{FVC}$ ratio $<50 \%$ or barrel-chest deformity, a level of severity which is rarely seen today. These children with SA may not be representative of current children with SA as subjects in this cohort were also managed at a time when corticosteroids were not available in clinical practice until they were in their late $20 \mathrm{~s}$ or $30 \mathrm{~s}$. As to whether inhaled corticosteroids have any impact on lung function of asthmatic subjects tracking into adult life, this has been addressed in the Dunedin cohort whereby subjects who were receiving inhaled corticosteroids had lower lung function at the ages of 18 and 26 compared with those not receiving inhaled corticosteroids, although this outcome may have been confounded by the severity of the underlying asthma. ${ }^{8} 37$

There are several limitations in our study including a reduced participation rate which may have led to selection bias. Despite this, we believe that our current study group is representative of the recruitment group. Data on questionnaires are also subject to recall errors. The definition of the asthma group was based on questionnaire data alone which in itself is prone to recall bias and possible error. Other risk factors such as candidate genes, prematurity, parental history of asthma, childhood respiratory infections, maternal smoking, occupational exposures to dusts and chemicals or biomass fuels are associated with the development of COPD but in this longitudinal study, data on these risk factors were not available. The small number of subjects who fulfilled the diagnosis of COPD is also a limitation and may affect the power of negative findings. Last, the absence of bronchial hyper-responsiveness testing in children does not allow measurement of its contribution as a risk factor towards adult COPD and on the decline in lung function.

In conclusion, children with SA are at increased risk of developing adult COPD, despite the absence of a smoking history. Children with intermittent and persistent asthma which accounts for the majority of childhood asthma are not at increased risk. The fixed abnormalities in lung function in adult life are clearly established in childhood and track at lower values progressing to irreversible airway obstruction in adulthood.

Correction notice This article has been corrected since it was published Online First. The author Nadeene Clark has been amended to read Nadeene Clarke.

Acknowledgements The authors thank the participants of this study.

Contributors Acquisition of data: AT, MR, HT, NC. Analysis and interpretation of data: AT, JW, CR. Drafting or revising the paper for important intellectual content and final approval of data: AT, MR, HT, NC, JW, CR.

Funding National Health Medical Research Council Australia, No. 436959.

\section{Competing interests None.}

Ethics approval Human Research Ethics Committee Royal Children's Hospital Melbourne.

Provenance and peer review Not commissioned; externally peer reviewed.

\section{REFERENCES}

1 Burrows B, Knudson RJ, Lebowitz MD. The relationship of childhood respiratory illness on adult obstructive airway disease. Am Rev Respir Dis 1977;115:751-60.

2 Sluiter HJ, Koeter GH, de Monchy JG, et al. The Dutch hypothesis (chronic non-specific lung disease) revisited. Eur Respir J 1991;4:479-89.

3 Silva GE, Sherrill DL, Guerra $S$, et al. Asthma as a risk factor for COPD in a longitudinal study. Chest 2004;126:59-65.

4 Svanes $C$, Sunyer J, Plana E, et al. Early life origins of chronic obstructive pulmonary disease. Thorax 2010;65:14-20.

5 Stern DA, Morgan WJ, Wright AL, et al. Poor airway function in early infancy and lung function by age 22 years: a non-selective longitudinal cohort study. Lancet 2007;370:758-64.

6 James AL, Palmer LJ, Kicic E, et al. Decline in lung function in the Busselton Health Study: the effects of asthma and cigarette smoking. Am J Respir Crit Care Med 2005;171:109-14.

7 Apostol G, Jacobs DR, Tsai AW, et al. Early life factors contribute to the decrease in lung function between ages 18 and 40: the Coronary Artery Risk Development in Young Adults study. Am J Respir Crit Care Med 2002;166:166-72.

8 Sears MR, Greene JM, Willan AR, et al. A longitudinal, population-based, cohort study of childhood asthma followed to adulthood. N Eng/ J Med 2003;349:1414-22.

9 Gold DR, Wang X, Wypij D, et al. Effects of cigarette smoking on lung function in adolescent boys and girls. N Engl J Med 1996;335:931-7.

10 Tai $A$, Tran $H$, Roberts $M$, et al. Pediatric origins of adult chronic obstructive pulmonary disease (COPD): Childhood asthma. Am J Respir Crit Care Med 2010;181:A2275.

11 Williams H, McNicol KN. Prevalence, natural history, and relationship of wheezy bronchitis and asthma in children. An epidemiological study. BMJ 1969;4:321-5.

12 McNicol KN, Williams H. Spectrum of asthma in children. 1. Clinical and physiological components. BMJ 1973;4(5883):7-11.

13 Martin AJ, McLennan LA, Landau LI, et al. The natural history of childhood asthma to adult life. BMJ 1980;280:1397-46.

14 Oswald $H$, Phelan PD, Lanigan A, et al. Childhood asthma and lung function in mid-adult life. Pediatr Pulmonol 1997;23:14-20.

15 Kelly WJ, Hudson I, Phelan PD, et al. Childhood asthma in adult life: a further study at 28 years of age. BMJ 1987;294:1059-62.

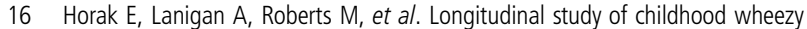
bronchitis and asthma: outcome at age 42. BMJ 2003;326:422-3.

17 Jones PW. Interpreting thresholds for a clinically significant changes in health status in asthma and COPD. Eur Respir J 2002;19:398-404.

18 Pellegrino R, Viegl G, Brusasco V, et al. Interpretative strategies for lung function tests. Eur Respir J 2005;26:948-68.

19 Celli BR, MacNee W. Standards for the diagnosis and treatment of patients with COPD: a summary of the ATS/ERS position paper. Eur Respir J 2004;23:932-46.

20 Backman KS, Greenberger PA, Patterson R. Airways obstruction in patients with long-term asthma consistent with 'irreversible asthma'. Chest 1997;112:1234-40.

21 Brown PJ, Greville HW, Finucane KE. Asthma and irreversible airflow obstruction. Thorax 1984;39:131-6. 
22 Bush A. COPD: A pediatric disease. COPD 2008:5:53-67.

23 Narang I, Bush A. Early origins of chronic obstructive pulmonary disease. Semin Fetal Neonatal Med 2012:17:112-8.

24 King ME, Mannino DM, Holguin F. Risk factors for asthma incidence: a review of recent prospective evidence. Panminerva Med 2004:46:97-110.

25 Salvi SS, Barnes PJ. Chronic obstructive pulmonary disease in non-smokers. Lancet 2009:374:733-43.

26 Lokke A, Lange P, Scharling H, et al. Developing COPD: a 25 year follow up study of the general population. Thorax 2006;61:935-9.

27 Beasley $R$, Weatherall $M$, Travers J, et al. Time to define the disorders of the syndrome of COPD. Lancet 2009;374:670-2.

28 Nakano Y, Muller NL, King GG, et al. Quantitative assessment of airway remodeling using high-resolution CT. Chest 2002;122:271-5.

29 McParland BE, Macklem PT, Pare PD. Airway wall remodelling: friend or foe? I Appl Physiol 2003;95:426-34.

30 Saglani S, Malmstrom K, Pelkonen AS, et al. Airway remodeling and inflammation in symptomatic infants with reversible airflow obstruction. Am I Respir Crit Care Med 2005;171:722-7.
31 Payne DN, Rogers AV, Adelroth E, et al. Early thickening of the reticular basement membrane in children with difficult asthma. Am J Respir Crit Care Med 2003;167:78-82.

32 Payne DN, Qiu Y, Zhu J, et al. Airway inflammation in children with difficult asthma: relationships with airflow limitation and persistent symptoms. Thorax 2004:59:862-9.

33 Elias JA. Airway remodeling in asthma: unanswered questions. Am J Respir Crit Care Med 2000;161:S168-71.

34 Davies DE, Wicks J, Powell RM, et al. Airway remodeling in asthma: new insights. J Allergy Clin Immunol 2003;111:215-25.

35 Ten Hacken NHT, Postma DS, Timens W. Airway remodeling and long term decline in lung function in asthma. Curr Opin Pulm Med 2003;9:9-14.

36 Benayoun L, Druilhe A, Dombret MC, et al. Airway structural alterations selectively associated with severe asthma. Am J Respir Crit Care Med 2003;167: $1360-8$.

37 Rasmussen F, Taylor DR, Flannery EM, et al. Risk factors for airway remodeling in asthma manifested by a low postbronchodilator FEV1/vital capacity ratio: a Iongitudinal population study from childhood to adulthood. Am J Respir Crit Care Med 2002;165:1480-8. 